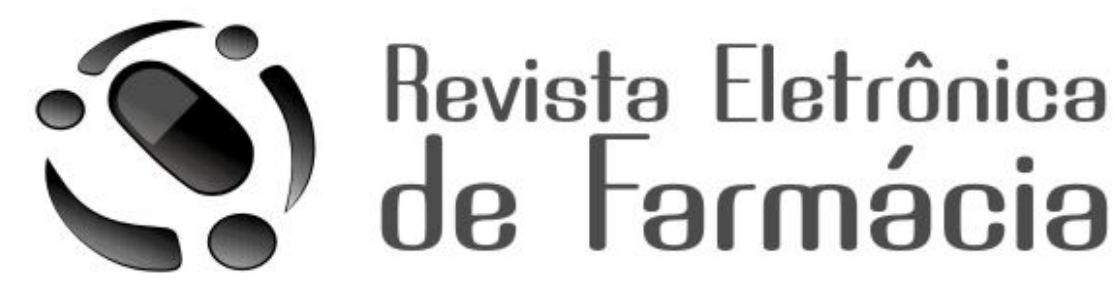

REF - ISSN 1808-0804 Vol. V (3), 71 - 78, 2008

\title{
EFEITO DA QUERCETINA SOBRE O CRESCIMENTO E ATIVIDADE HEMOLÍTICA DE Staphylococcus aureus
}

Effect of quercetin on Staphylococcus aureus growth and hemolytic activity

Mariana Santoro de Camargo; Maria Stella Gonçalves Raddi ${ }^{\star}$

Departamento de Análises Clínicas da Faculdade de Ciências Farmacêuticas de

Araraquara, UNESP - Universidade Estadual Paulista

Rua Expedicionários do Brasil, 1621, CP 503, CEP 14801-902, Araraquara - SP - Brasil.

*Autor para correspondência: raddims@fcfar.unesp.br

Recebido em 22/10/2008 - Aceito em 01/12/2008

RESUMO: Os flavonóides são compostos polifenólicos com ampla distribuição no reino vegetal. Quercetina, composto pertencente à classe dos flavonóis, está presente em diversos alimentos e exerce múltiplas atividades farmacológicas. Em decorrência da necessidade de novas opções terapêuticas nas doenças infecciosas, ênfase no estudo da atividade antimicrobiana de flavonóides teve destaque nos últimos anos. Esse estudo avaliou o efeito pós-antimicrobiano (EPA) e modulação na atividade de hemolisinas da concentração subinibitória de quercetina em Staphylococcus aureus (ATCC 25923). A atividade antibacteriana foi determinada através do método de microdiluição em caldo, sendo a concentração de $40 \mu / \mathrm{mL}$ utilizada como subinibitória. Quercetina demonstrou não apresentar EPA nessa concentração, mas diminuiu a atividade de hemolisinas extracelulares para hemácias de carneiro. Essas observações sugerem que outras toxinas danificadoras de membrana relacionadas à virulência de $S$. aureus possam ser moduladas por esse flavonol, interferindo na capacidade do microrganismo em danificar o hospedeiro.

PALAVRAS-CHAVES: quercetina, Staphylococcus aureus, proteínas hemolisinas

ABSTRACT: Flavonoids are polyphenols widely distributed in the vegetal kingdom. Quercetin, the major representative of a class of flavonoids called flavonols, is abundant in foods and exerts multiple pharmacologic properties. Based on the necessity of novel therapeutic strategies to treat infectious illness, emphasis on study of the antimicrobial activity of flavonoids in last year's has been of significance. This study evaluated the post-antimicrobial effect (PAE) and the modulation in the hemolysins activity of the sub-inhibitory concentration of quercetin on Staphylococcus aureus. (ATCC 25923). The antibacterial activity was evaluated by broth micro dilution method and the concentration of the $40 \mu / \mathrm{mL}$ was used as sub-inhibitory. Quercetin did not exhibit PAE in this concentration but reduced the extracellular activity of hemolysins for 
Camargo, M. S.; Raddi, M. S. G./ Revista Eletrônica de Farmácia Vol 5 (3), 71 - 78, 2008.

sheep erythrocytes. These results suggest that others membrane damage toxins related to virulence factors can be modulated by this flavonol interfering with the capacity of the microorganism in damaging the host.

KEYWORDS: quercetin, Staphylococcus aureus, hemolysin proteins

\section{INTRODUÇÃO}

Os flavonóides são compostos polifenólicos de ampla distribuição no reino vegetal, agrupados em várias classes: flavona, flavonol, flavanona, isoflavona, chalcona, aurona, entre outras (ZUANAZZI, 1999). Dentre os flavonóis, a quercetina (3,3',4',5,7-pentahidroxiflavona) é uma aglicona que está presente em diversos alimentos, como alho, cebola, alface, brócolis, maçã, azeitona, uva, entre outros, e exerce múltiplas atividades farmacológicas (SKIBOLA \& SMITH, 2000).

O consumo diário da quercetina pode estar associado à diminuição do risco de doenças cardiovasculares, desenvolvimento de tumores, derrames cerebrais e doenças neurodegenerativas (RATNAN et al., 2006) que são justificados pela proteção contra danos oxidativos ao DNA (FAROMBI, 2006), peroxidação lipídica (LIMA et al, 2006) e inibição da liberação de mediadores da inflamação (CHO et al, 2003).

Estudos in vivo demonstraram que a administração oral de quercetina protege animais de laboratório contra infecção induzida por Shigella (VIJAYA \& ANANTHAN, 1996) e, posteriormente, DASTIDAR et al. (2004) comprovaram, em ratos, que a administração intraperitoneal de uma isoflavona (sophoraisoflavone A) induz proteção contra Salmonella typhimurium.

Staphylococcus aureus, apesar de ser um microrganismo comensal da pele e mucosas, é um importante patógeno tanto em infecções comunitárias como hospitalares (TORTORA et al, 2000). Esse microrganismo sintetiza uma variedade de exotoxinas direcionadas ao metabolismo da célula hospedeira. Dentre essas toxinas, as hemolisinas são relatadas ter atividade citolítica, hemolítica e tóxica, sendo a alfa-toxina a mais estudada (DINGES et al, 2000; KAWATE \& GOUAUX, 2003).

Nas últimas décadas foram frequentes os relatos sobre a influência de diversos grupos de substâncias químicas, incluindo antimicrobianos, na estrutura e metabolismo dos microrganismos. Essas substâncias, quando em concentração ou tempo insuficiente para causar morte ou inibição total do crescimento, causam modificações nas propriedades bacterianas que podem refletir em alterações de componentes somáticos e produtos extracelulares (GALICE et al., 2006; HOWARD et al, 1993; WU et al, 1995).

Em decorrência da necessidade de novas opções terapêuticas, ênfase no estudo da atividade antimicrobiana de flavonóides teve destaque nos últimos anos. Assim, consideramos importante avaliar as alterações induzidas pela quercetina sobre o crescimento e expressão de hemolisinas de $S$. aureus visando oferecer subsídios adicionais para o emprego desse flavonol como antibacteriano na clínica médica.

\section{MATERIAL E MÉTODOS}

\section{Preparo da solução de quercetina}

Quercetina (Q0125, Sigma, St. Louis, MO, USA) foi dissolvida em dimetilsulfóxido (DMSO) (Sigma D8779) a 10mg/mL. A partir dessa solução foram realizadas diluições seriadas (0.46 a $120 \mu \mathrm{g} / \mathrm{mL}$ ) em caldo Müeller-Hinton (Difco, Detrot, MI). A concentração máxima de DMSO utilizada não interferiu no crescimento bacteriano. 
Camargo, M. S.; Raddi, M. S. G./ Revista Eletrônica de Farmácia Vol 5 (3), 71 - 78, 2008.

\section{Avaliação da atividade antibacteriana da quercetina para Staphylococcus aureus}

O efeito da quercetina sobre o crescimento de Staphylococccus aureus ATCC 25923 (Fundação Oswaldo Cruz, RJ, Brazil) foi determinado utilizando-se o método espectrofotométrico de microdiluição (DEVIENNE \& RADDI, 2002). Orifícios de microplacas foram preenchidos com $100 \mu \mathrm{L}$ de caldo Müeller-Hinton contendo diferentes concentrações do flavonóide e $100 \mu \mathrm{L}$ da suspensão bacteriana em crescimento exponencial em UDO 620 0,10 (espectrofotômetro multicanal Spectra (Shell) \& Rainbow (Shell) Readers da Tecan Austria Ges.m.b.H). A inibição do crescimento foi determinada através da diferença de absorvância obtida antes e após incubação da placa por 24 horas, a $37 \stackrel{\circ}{ } \mathrm{C}$. Os ensaios foram realizados em triplicata e repetidos, no mínimo, três vezes. Como controle do crescimento, $100 \mu \mathrm{L}$ de caldo sem o flavonóide foram adicionados ao mesmo volume da suspensão bacteriana. Os resultados foram utilizados para a determinação da concentração subinibitória empregada nos testes propostos.

\section{Avaliação do efeito pós-antimicrobiano (EPA) da concentração subinibitória de quercetina no crescimento de $S$. aureus}

O EPA da quercetina sobre o crescimento bacteriano foi realizado de acordo com a metodologia proposta por Tessier et al (2000). Suspensão bacteriana, em fase exponencial de crescimento, foi acrescida de infusão cérebro e coração (Brain Heart Infusion, BHI) e BHI contendo a concentração subinibitória de quercetina, volume a volume. Após incubação por 2024 horas a $35-37^{\circ} \mathrm{C}$, os tubos foram centrifugados a $800 \times \mathrm{g}$ por 10 minutos, as células bacterianas lavadas três vezes com solução salina tamponada (PBS, pH 7,2), ressuspendidas em BHI e padronizadas a $U_{D O} 0,10$. Duzentos e cinqüenta microlitros $(250 \mu \mathrm{L})$ de cada suspensão foram transferidos para orifícios de microplaca, a qual foi incubada a $35-37^{\circ} \mathrm{C}$. Leituras espectrofotométricas a $\mathrm{UDO}_{620}$ foram realizadas de $30 \mathrm{em} 30$ minutos, durante 8 horas. Os experimentos foram realizados em triplicata e repetidos por três vezes.Os dados foram analisados, comparativamente, através da relação direta entre absorvância e tempo de incubação.

\section{Determinação do efeito da concentração subinibitória de quercetina na atividade de hemolisinas extracelulares de $S$. aureus}

A atividade hemolítica do sobrenadante de cultura de $S$. aureus foi avaliada segundo metodologia descrita por Smith-Palmer et al. (2004), com algumas modificações. Cultura de $S$. aureus, em fase exponencial de crescimento, em BHI $\left(\mathrm{UDO}_{620} 0,10\right)$, foi transferida para o mesmo caldo na ausência e presença da concentração subinibitória de quercetina. Os tubos foram incubados por $20-24$ horas a $35-37^{\circ} \mathrm{C}$, padronizados em mesma absorvância em comprimento de onde de $620 \mathrm{~nm}$ e centrifugados a $800 \times \mathrm{g}$, por 15 minutos. A $2 \mathrm{~mL}$ do sobrenadante filtrado foi adicionado $1 \mathrm{~mL}$ de suspensão de hemácias de carneiro a $1 \% \mathrm{em}$ PBS, pH 7,2. Como controle de ausência de hemólise e hemólise total, o mesmo volume do sobrenadante da cultura bacteriana foi substituído por tampão fosfato e água destilada, respectivamente. Após incubação a $37^{\circ} \mathrm{C}$, por 45 minutos, os tubos foram centrifugados a $800 \mathrm{x}$ $\mathrm{g}$ por 10 minutos e os sobrenadantes foram, cuidadosamente, transferidos para orifícios de microplaca (96 orifícios) para leitura das absorvâncias a $540 \mathrm{~nm}$. Os resultados foram expressos em porcentagem de hemólise em relação ao controle de hemólise total (100\%). Os ensaios foram realizados em triplicata e repetidos por três vezes.

\section{Análise estatística}


Camargo, M. S.; Raddi, M. S. G./ Revista Eletrônica de Farmácia Vol 5 (3), 71 - 78, 2008.

A interpretação dos resultados foi realizada através de análise de variância (ANOVA), sendo 0,05 o nível de significância (LAPPONI, 1997).

\section{RESULTADOS E DISCUSSÃO}

Nos últimos anos, compostos fenólicos, dentre eles os flavonóides, vêm merecendo grande atenção. Há concordância quanto à atividade antibacteriana de extratos de plantas, demonstrada através de uma interminável lista de publicações, contudo, não há um consenso quando as substâncias puras são testadas isoladamente. A atividade antibacteriana da quercetina, um dos flavonóides mais estudados, apresenta discrepância de resultados, provavelmente decorrente de diferentes cepas e técnicas utilizadas nas investigações. A concentração inibitória mínima (CIM) para S. aureus (ESR \# 917), determinada por Parkar et al. (2008), através da técnica espectrofotomética de microdiluição em caldo, foi de $62,5 \mu \mathrm{g} / \mathrm{mL}$; Kang et al. (2006) não conseguiram definir a atividade inibitória desse flavonol para $S$. aureus cepa Newman (CIM > $300 \mu \mathrm{g} / \mathrm{mL}$ ) utilizando a mesma técnica. Cushnie \& Lamb (2005), em extensa revisão sobre a atividade antimicrobiana de flavonóides, abordam variações que justificam as discrepâncias relatadas na literatura além da cepa utilizada.

O efeito da quercetina sobre o crescimento de $S$. aureus (ATCC 25923), determinado através de técnica espectrofotométrica de microdiluição, demonstrou que esse flavonol, na maior concentração ensaiada $(120 \mu \mathrm{g} / \mathrm{mL})$, inibiu $70 \%$ do crescimento bacteriano em relação ao controle (Fig. 1). Através de análise de regressão linear, a concentração de $40 \mu \mathrm{g} / \mathrm{mL}$ foi definida como subinibitória para a realização dos demais experimentos, visto representar a concentração de quercetina que inibe $50 \%$ do crescimento bacteriano. Durante a realização desse trabalho, verificamos a precipitação do flavonóide em soluções de altas concentrações e durante o armazenamento (-20ํㅡ), sendo a solução de uso preparada no momento de cada prática.

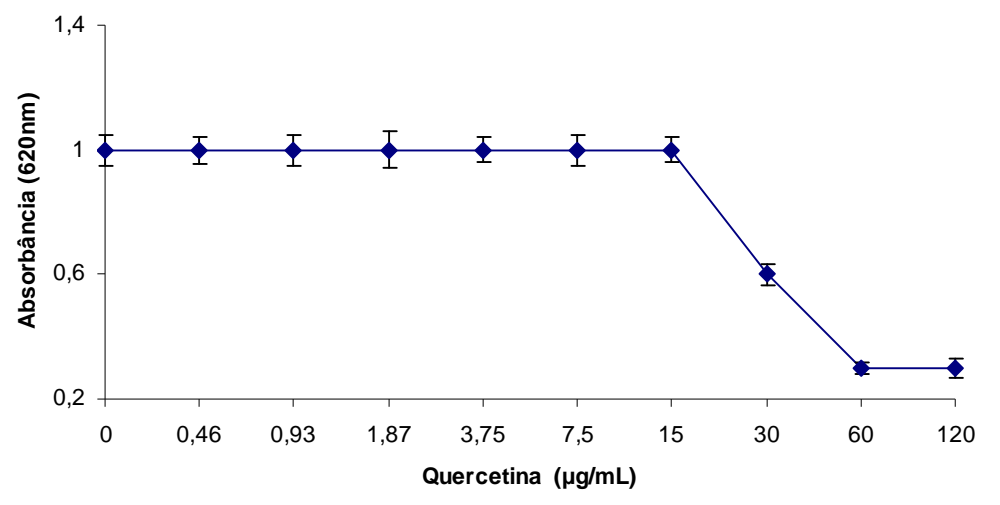

Figura 1 - Efeito de diferentes concentrações de quercetina na inibição do crescimento de Staphylococcus aureus

Efeito pós-antimicrobiano (EPA) é o termo utilizado para descrever a supressão do crescimento bacteriano que persisti após a exposição do microrganismo a um agente antimicrobiano. Diferentes metodologias podem ser empregadas para quantificar o crescimento de uma população bacteriana. Os métodos diretos determinam o número de células, enquanto os métodos indiretos analisam a massa da população que é diretamente proporcional ao número de células bacterianas (TORTORA et al, 2000). A técnica espectrofotométrica de microdiluição, método indireto empregado para monitorar o crescimento bacteriano, foi utilizada 
Camargo, M. S.; Raddi, M. S. G./ Revista Eletrônica de Farmácia Vol 5 (3), 71 - 78, 2008.

para demonstrar o EPA da quercetina no crescimento de $S$. aureus. A Figura 2 apresenta a curva de crescimento de $S$. aureus, por um período de 8 horas, após exposição à concentração subinibitória de quercetina

O EPA é um mecanismo dependente da recuperação celular dos danos induzidos pela droga e é apontado como favorável em diversas situações clínicas (ODENHOLT, 2001). Os benefícios do EPA de amoxicilina sobre algumas espécies de Streptococcus foram apontados como benéficos na profilaxia de infecções em procedimentos dental/oral (LEE et al., 2000). Nossos resultados demonstram que a supressão do crescimento induzida pela quercetina não é mantida após a sua remoção $(p=0,215939)$, sugerindo que esse flavonol não induz danos na célula bacteriana envolvidos no crescimento que necessitam de reparação. A literatura relata que bactérias expostas a antimicrobianos que interferem na síntese protéica apresentam a fase lag do crescimento estendida, na qual ocorre reparação do dano no DNA provocado pela exposição ao antimicrobiano (HOWARD et al., 1993).

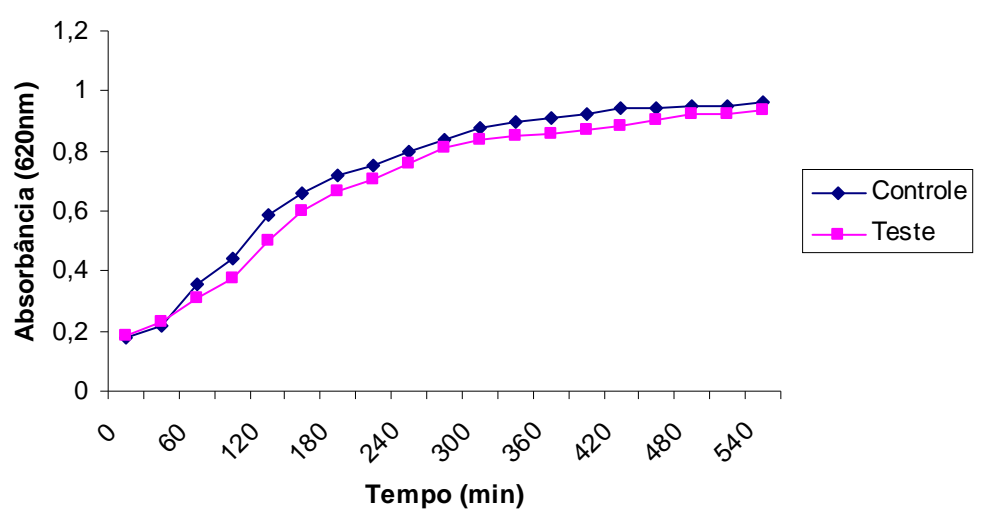

Figura 2 - Efeito da concentração sub-inibitória $(40 \mu \mathrm{g} / \mathrm{mL})$ de quercetina no crescimento de Staphylococcus aureus

Das, aproximadamente, 220 toxinas bacterianas conhecidas, cerca de $40 \%$ lesam membranas de células eucarióticas (TORTORA et al, 2000). De um modo geral, as citolisinas formadoras de poro compartilham mecanismo de ação semelhante, que envolve ligação à membrana, seguida de sua inserção, oligomerização e formação de poro. A expressão da $\alpha$ toxina tem sido objetivo de vários estudos, sendo reconhecido que sub-CIMs de aminoglicosídeos diminuem os níveis de expressão e os $\beta$-lactâmicos aumentam, drasticamente, sua produção (WORLITZSCH et al, 2001). Através da metodologia utilizada, os resultados demonstraram que quercetina, na concentração de $40 \mu \mathrm{g} / \mathrm{mL}$, diminuiu a atividade de hemolisinas extracelulares (Fig. 3). A diminuição na atividade hemolítica de S.aureus induzida por esse flavonol deve ser avaliada com cautela, tendo em vista que Oksun et al. (2007) relataram a formação de agregados entre polifenóis e a-toxina, o que impede a quantificação dessa citolisina pela técnica empregada. Todavia, outras toxinas, com atividade hemolítica podem estar sendo inibidas. 


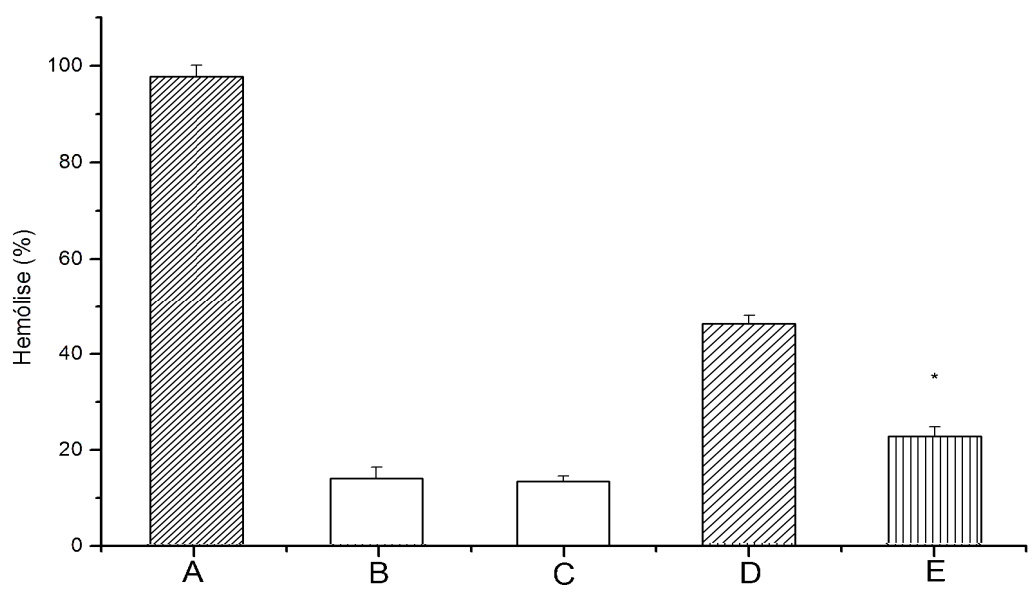

Figura 3 - Atividade hemolítica para hemácias de carneiro: (A) Controle de hemólise total, (B) Controle de ausência de hemólise, (C) Controle de hemólise da quercetina $(40 \mu \mathrm{g} / \mathrm{mL})$, (D) Hemólise do sobrenadante da cultura de $S$. aureus na ausência de quercetina, (E) Hemólise do sobrenadante da cultura de $S$. aureus na presença da concentração subinibitória de quercetina $(40 \mu \mathrm{g} / \mathrm{mL})\left({ }^{*} \mathrm{p}=0,025770\right)$.

\section{CONCLUSÕES}

Considerando as informações disponíveis na literatura e as limitações das técnicas utilizadas, a análise dos resultados permite-nos concluir que quercetina, na concentração subinhibitória, tem a capacidade de inibir a expressão de hemolisinas sem apresentar EPA em $S$. aureus (ATCC 25923). Essas observações sugerem que outros fatores relacionados à virulência de $S$. aureus possam ser modulados por esse flavonol interferindo na capacidade do microrganismo em danificar o hospedeiro.

\section{REFERÊNCIAS BIBLIOGRÁFICAS}

CHO, S. Y.; PARK, S. J.; KWON, M. J.; JEONG, T. S.; BOK, S. H.; CHOI, W. Y.; JEONG, W. I.; RYU, S. Y.; DO, S. H.; LEE, C. S.; SONG, J. C.; JEONG, K. S. Quercetin suppresses proinflammatory cytokines production through MAP kinases andNF-kappaB pathway in lipopolysaccharide-stimulated macrophage. Mol. Cell. Biochem., v.243, p. 153-160, 2003.

CUSHNIE, T. P.; LAMB, A. J. Antimicrobial activity of flavonoids. Int. J. Antimicrob. Agents, v. 25, p. 343-356, 2005.

DASTIDAR, S. G.; MANNA, A.; KUMAR, K. A.; MAZUMDAR, K; DUTTA, N. K.; CHAKRABARTY, A. N.; MOTOHASHI, N.; SHIRATAKI, Y. Studies on the antibacterial potentiality of isoflavones. Int. J. Antimicrob. Agents, v. 23, p. 99-102, 2004.

DEVIENNE, K. F.; RADDI, M.S.G. Screening for antimicrobial activity of natural products using a microplate photometer. Braz. J. Microbiol., v. 33, p. 166-168, 2002. 
Camargo, M. S.; Raddi, M. S. G./ Revista Eletrônica de Farmácia Vol 5 (3), 71 - 78, 2008.

DINGES, M. M.; ORWIN, P. M.; SCHLIEVERT, P. M. Exotoxins of Staphylococcus aureus. Clin. Microbiol. Rev., v. 13, p. 16-34, 2000.

FAROMBI, E. O. Genotoxicity of chloroquine in rat liver cells: protective role of free radical scavengers. Cell. Biol. Toxicol., v. 22, p. 159-167, 2006.

GALICE, D. M.; BONACORSI, C.; SOARES, V. C.; RADDI, M. S.; FONSECA, L. M. Effect of subinhibitory concentration of chlorhexidine on Streptococcus agalactiae virulence factor expression. Int. J. Antimicrob. Agents., v. 28, p. 143-146, 2006.

HOWARD, B. M. A.; PINNEY, R. J.; SMITH, J. T. Contribuitions of post-antibiotic lad and repairrecovery to the pos-antibiotic effects of ciprofloxacin on Escherichia coli, Klebsiella pneumoniae, Staphylococcus aureus and Streptococcus pyogenes. Chemotherapy, v. 39, p. 22 - 31, 1993.

KANG, S. S.; KIM, J. G.; LEE, T. H.; OH, K. B. Flavonols inhibit sortases and sortase-mediated Staphylococcus aureus clumping to fibrinogen. Biol. Pharm. Bull., v. 29 p. 1751-1755, 2006.

KAWATE, T.; GOUAUX, E. Arresting and releasing Staphylococcal alpha-hemolysin at intermediate stages pore formation by engineered disulfide bonds. Protein Sci., v.12, p.9971006, 2003.

LEE, L.Y. Postantibiotic effects and postantibiotic sub-MIC effects of amoxicillin on Streptococcus gordonii and Streptococcus sanguis. J. Chemother., v. 12, p.379-384, 2000.

LAPONI, J.C. Estatística: usando Excel 5 e 7. São Paulo: Lapponi, 1997. 420p.

LIMA, C. F; FERNANDES-FERREIRA, M.; PEREIRA-WILSON, C. Phenolic compounds protect HepG2 cells from oxidative damage: relevance of glutathione levels. Life Sci., v. 79, p. 20562068, 2006.

ODENHOLT, I. Pharmacodynamic effects of subinhibitory antibiotic concentrations. Int. J. Antimicrob. Agents, v. 17, p. 1-8, 2001.

OKSUN, C.; KINNOSUKE, Y.; NAOKO, M.; MIYAKASI, M.; NODA, M. Inhibitory effects of various plants polyphenols on the toxicity of Staphylococcal a-toxin. Microbial. Pathogenesis, v. 42, p. 215-224, 2007.

PARKAR, S. G.; STEVENSON, D. E.; SKINNER, M. A. The potential influence of fruit polyphenols on colonic microflora and human gut health. Int. J. Food Microbiol., v. 124, p. 295298, 2008.

RATNAN, D. V.; ANKOLA, D. D.; BHARDWAJ, V.; SAHANA, D. K.; KUMAR, M. N. Role of antioxidants in prophylaxis and therapy: A pharmaceutical perspective. J. Control Release, v. 113, p. 189-207, 2006.

SKIBOLA, C. F.; SMITH, N. T. Potential health impacts of excessive flavonoid intake. Free Radical Biol. Med., v. 29, p. 375-383, 2000.

SMITH-PALMER, A; STEWART, J.; FYFE, L. Influence of subinhibitory concentrations of plants essential oils on the production of enterotoxins A and B and $\alpha$-toxin by Staphylococcus aureus. J. Med. Microbiol., v. 53, p. 1023-1027, 2004. 
Camargo, M. S.; Raddi, M. S. G./ Revista Eletrônica de Farmácia Vol 5 (3), 71 - 78, 2008.

TESSIER, P. R.; NIGHTINGALE, C. H.; NICOLAU, D. P. Postantibiotic effect of trovafloxacin against Streptococcus pneumoniae, Haemophilus influenzae, and Neisseria meningitidis in cerebrospinal fluid and broth culture media. Diagn. Microbiol. Infect. Dis.,v. 36, p. 241-247, 2000 .

TORTORA, G. R.; FUNKE, B. R.; CASE, C. L. Microbilogia. Porto Alegre: ARTMED Editora, 6 ed., 827p., 2000.

VIJAYA, K.; ANANTHAN, S. Therapeutic efficacy of medicinal plants against experimentally induced shigellosis in guinea pigs. Indian J. Pharm. Sci., v. 58, p. 191-193, 1996.

WORLITZSCH, D.; KAYGIN, H.; STEINHUBER, A.; DALHOFF, A.; BOTZENHART, K.; DORING, G. Effects of amoxicillin, gentamicin, and moxifloxacin on the hemolytic activity of Staphylococcus aureus in vitro and in vivo. Antimicrob. Agents Chemother., v.45, p. 196-202, 2001.

WU, Q., WANG, Q. I., TAYLOR, K. G., DOYLE, R. J. Subnhibitory concentrations of antibiotics affect cell surface properties of Streptococcus sobrinus. J. Bacteriol., v. 177, p. 1399-1401, 1995.

ZUANAZZI, J. A. S. Flavonóides. In: SIMÕES, C. M. O.; SCHENKEL, E. P.; GOSMANN, G.; MELLO, J. C. P.; MENTZ, L. A.; PETRVIK, P. R. Farmacognosia da planta ao medicamento. Rio Grande do Sul: Ed. UFRGS; Ed. UFSC, 1999, p. 517-545. 